\title{
Influence of Plant Metabolites on Flea Beetle Infestation in Spider Plant Morphotypes
}

\author{
Gatahi Dennis Maina ${ }^{1}$, Wanyika Harrison ${ }^{2}$, Gohole Linnet ${ }^{3}$, Evans Ligare Chimoita ${ }^{4, *}$ \\ ${ }^{1}$ Department of Horticulture; Jomo Kenyatta University of Agriculture and Technology, Nairobi \\ ${ }^{2}$ Department of Chemistry; Jomo Kenyatta University of Agriculture and Technology, Nairobi \\ ${ }^{3}$ Department of crop Science, University of Eldoret, Eldoret \\ ${ }^{4}$ Department of Agricultural Economics, University of Nairobi, Kenya
}

Copyright (C) 2015 Horizon Research Publishing All rights reserved.

\begin{abstract}
Flea beetle is an important pest accounting for $25 \%$ foliage damage in spider plant. The reported damage manifested as "shot holes" is variable among the spider plant morphotypes. The study aimed at determining the damage inflicted on three main morphotypes in relation to metabolites. Three spider plant morphotypes were propagated inside a screen house on a completely randomised design (CRD) and flea beetles introduced on the seventh week of growth to determine the damage caused and assessed using the Bailey scoring scale (0-3, 4-7 and $>7$ holes/leaf). Data on damage was log transformed and analysed using analysis of variance (ANOVA). The means were separated using protected least significant difference $\left(\mathrm{LSD}_{0.05}\right)$. Quantitative determination of primary and secondary metabolites was done on the foliage taken before infestation. Proximate and Kjedahl methods were used to determine carbohydrates and proteins respectively. Determination of the secondary metabolites and vitamins was done using chromatography. The purple stemmed morphotype was most damaged $(8.6, \mathrm{p} \leq 0.05)$, green stemmed morphotype least damaged $(2.7, \mathrm{p} \leq 0.05)$, while the purple-green morphotype was moderately damaged (7.6, $\mathrm{p} \leq 0.05$ ). There was a significant difference of metabolites among the morphotypes. Purple stemmed had highest carbohydrates, proteins, vitamins and glucosinolates but least terpenoids while green stemmed morphotype had the least primary metabolites and glucosinolates but highest terpenoids. The purple stemmed morphotype was most susceptible and green stemmed morphotype was least susceptible. The inflicted damage was largely metabolomically influenced and that primary metabolites and glucosinolates levels were antagonistic to the terpenoids levels in the morphotypes. It can be recommended that, plant breeders use the green stemmed morphotype to improve resistance of the more nutritious but flea beetle susceptible purple stemmed morphotype in order to increase yield and maintain the nutritional potential. Also farmers can grow green stemmed morphotype in flea beetle infested fields.
\end{abstract}

Keywords Flea Beetle, Spider Plant, Morphotype, Plant Metabolites, Damage

\section{Introduction}

Spider plant (Cleome gynandra L.) Linnaeus, 1753 forms a significant part of the most consumed African leafy vegetables (ALVs) in Western and Rift valley provinces of Kenya. It forms $7 \%$ of the total ALVs consumption in these regions [1]. The crop is preferred due to its high nutritional profile, therapeutic role and ease of production. The crop has also been ingrained in the culture of these communities forming an integral dietary component. Due to this significant role, any inimical condition to the production of the crop is a matter of concern.

Spider plant is well adapted to these regions although some pests have been found to attack it and reduce the yield. Among the major pests include; flea beetles, bragada bug, aphids and nematodes. However, it is the flea beetle (Phyllotretamashonana) Linnaeus, 1758 infestation that has been reported to cause the greatest damage [4]. The pest if left unabated and in severe infestation can result in total crop failure while moderate infestation leads to at least $25 \%$ foliage damage characterized by "shot holes" on the foliage. Determination of the actual damage caused by the flea beetles per morphotype was necessary in documentation and scientific validation of the Western and Rift Valley provinces of Kenya indigenous communities' observation that the damage varies across the morphotypes. The study investigated the variation existing between the spider plant morphotypes in terms of flea beetle damage and metabolites thereby offering a scientific explanation to the role of metabolites on flea beetle damage variation in spider plant morphotypes.

Spider plant morphotypes have been differentiated morphologically and dendrogramatically into three main morphotypes [22]. There are other emerging differences which have not been documented, for instance [1], in her analysis of the spider plant morphotypes described the purple stemmed morphotype as being more nutritious and 
susceptible to diseases than the other morphotypes. In addition to [1] report, many farmers in Western and Rift Valley provinces have found out that the spider plant morphotypes have exhibited variable damage caused by the flea beetles.

This study anticipated that just like the morphotypes varied in the morphological and dendrogramatical characteristics, the metabolites, that is, primary and secondary also varied. Attributing the variation of damage by the flea beetles to the metabolites was informed by the fact that metabolites play a great role in host plant desirability by the pests. This is due to the fact that, metabolites play the attractant or repellent role. Terpenoids which are produced in variable quantities by plants deter feeding by insect pests while other metabolites like glucosinolates and primary metabolites act as feeding stimulants [17]. The study investigated the primary metabolites, secondary metabolites and flea beetle damage caused per spider plant morphotype as this has not been documented.

The research aimed at generating important information on increasing the quality and quantity of spider plant yield by utilizing the inherent host-plant resistance attributes of the morphotypes in order to make cultivation of the crop attractive to more farmers and the product to fetch higher prices in the market due to improved yield and quality respectively.

\section{Materials and Methods}

\subsection{Seed Collection and Multiplication}

Farmers from Moiben and Kitale in Rift Valley and Chavakali in Western Province, Kenya provided the seeds to be used in the experiments. The sites were chosen based on a previous survey conducted by [1]. In the survey, valuable information on the scale of production, usefulness of the spider plant as a vegetable to the local people and reports by the local farmers that the flea beetles affected the foliage quality albeit in variable proportions among the morphotypes was obtained. Seeds of the three spider plant morphotypes were collected from the farmers' fields at the brown pod stage which is the harvest maturity stage and dried in the green house for two months to break the dormancy. The seeds were then sown in plastic pots (Ø 20 $\mathrm{cm}$ ) inside the green house for seed multiplication. The seedlings were closely monitored throughout the growing period and similar morphotypes grouped together to obtain true to type morphotypes of purple, purple-green and green stemmed spider plant which were used for the experiment.

\subsection{Experimental Site and Layout}

A one year host plant preference trial was set up in a screen house at the Department of Seed, Crop and Horticultural Sciences, University of Eldoret $\left(0^{\circ} 30^{\prime \prime} \mathrm{N}\right.$ and latitude $35^{\circ} 15^{\prime \prime} \mathrm{E}$ and 2140 meters above sea level)
The experiment was laid in a CRD with three treatments, replicated six times. The treatments were the three spider plant morphotypes (purple, purple-green and green stemmed). The plants were thinned to two plants per pot at the $4^{\text {th }}$ week after planting (WAP).

\subsection{Data Collection on Spider Plant Damage}

Flea beetles were introduced on the $7^{\text {th }}$ WAP at a rate of five beetles per plant. Data on foliage damage was taken after every two days for two weeks after infestation. The two days timing in data collection was selected based on the time required for the flea beetle to inflict significant damage, while the seventh week period taken before infestation of plant with flea beetles was determined by the time nutrients and biochemical's are at their optimum [11]. While taking the data, number of 'shot holes' were counted on all the leaves of the tagged plants where in each plot, six plants were randomly taken and tagged to be used in estimating the damage. Three leaves observed to be flea beetle damaged were selected and marked from the tagged plants and the average number of holes taken by physical counting through direct observation. For easy observation, a magnifying glass was used to show the shot holes clearly. [7] scoring scale was used for indexing the inflicted damage.

\section{Metabolites analysis}

Leaves of the three spider plant morphotypes were obtained after seven weeks of growth just before infestation with the flea beetles for metabolites analysis.

\section{Primary metabolites analysis}

The total primary metabolites were analysed using the proximate test for carbohydrates and micro-Kjedahl method for proteins as stipulated by [21]. In the laboratory, the leaves were ground into fine powder using a miller machine.

\section{Moisture Content}

Steel containers were heated at $110^{\circ} \mathrm{C}$ for 2 hours to obtain a constant weight. They were then cooled in a silica gel dessicator. A $20 \mathrm{~g}$ sample of ground spider plant morphotype was added to the container, then heated on an oven at $110^{\circ} \mathrm{C}$ for 2 hours and placed in the dessicator to cool. The constant weight of the sample was taken and the moisture content calculated as a difference of the sample weight before drying and after drying in the oven.

\section{Crude Fibre}

$20 \mathrm{~g}$ samples of ground spider plant morphotype were placed in $500 \mathrm{ml}$ beakers and dilute sulphuric acid added, then placed in refluxing chambers to digest the sample. The digest was filtered using a glass wool and rinsed with sodium hydroxide to remove the acid. Refluxing was continued using sodium hydroxide for 30 minutes and the sample filtered and washed with boiling water. The residue was washed with dilute Hydrochloric acid and rinsed with water to remove the acid. The residue was then washed once with absolute ethanol and three times with diethyl ether and dried 
in an oven at $100^{\circ} \mathrm{C}$ for 1 hour then cooled in a dessicator. The sample was then incinerated at $500^{\circ} \mathrm{C}$ for 1 hour and cooled in a dessicator. The crude fibre was calculated as a difference of the original mass and the weight after desiccation for all the three samples.

\section{Crude Ash}

The crucible was heated at $550^{\circ} \mathrm{C}$ for 1 hour and cooled in a dessicator then weighed. A $20 \mathrm{~g}$ sample of ground spider plant morphotype was placed in the dessicator for 2 hours; this was repeated until a constant weight was attained. The crude ash was calculated as a difference of the weight before placing in the oven and the weight after heating in the oven.

\section{Crude Fat}

A $20 \mathrm{~g}$ sample of ground spider plant morphotype was put in a thimble, placed in an oven at $100^{\circ} \mathrm{C}$ for 1 hour and cooled in a dessicator. The sample was then added in to a round bottomed flask containing diethyl ether and heated at $110^{\circ} \mathrm{C}$ for 18 hours, then cooled in a dessicator and weighed. Crude fat content was calculated as a difference of the sample weight before and after extraction of fat.

\section{Crude Protein}

A $20 \mathrm{~g}$ sample of ground spider plant morphotype was placed in the digestion flasks, mixed with sulphuric acid and copper sulphate as the catalyst. A blank test was prepared separately and sulphuric acid added. The two, that is, the sample and blank test were heated under a digestion heater until the colour changed to green like the blank. The samples were then transferred to distillation using the Marknan method and Titration done using hydrochloric acid until the orange colour occurred. The colour change was used to determine the amount of $\mathrm{N}$ per morphotype. The amount of nitrogen was calculated which was then used to obtain the quantity of protein using the formula below.

$$
\frac{N(\%)=(\mathrm{VHCl} * \mathrm{NHCl})-(\mathrm{VBK} * \mathrm{NNaOH})-(\mathrm{VNaOH} * \mathrm{NNaOH})}{1.4007 \mathrm{~W} / 100}
$$

Where;

$\mathrm{VHCl}$ - Volume $(\mathrm{mL})$ of standard $\mathrm{HCl}$ pipetted into titrating flask for sample

$\mathrm{NHCl}$ - Normality of $\mathrm{HCl}$

$\mathrm{VBK}$ - Volume (mL)of standard $\mathrm{NaOH}$ needed to titrate $1 \mathrm{~mL}$ standard $\mathrm{HCl}$ minus B

B -Volume (mL) of standard $\mathrm{NaOH}$ needed to titrate reagent blank carried through the method and distilled into $1 \mathrm{~mL}$ standard $\mathrm{HCl}$

$\mathrm{NNaOH}$-Normality of $\mathrm{NaOH}$

$\mathrm{VNaOH}$ - Volume (mL) of standard $\mathrm{NaOH}$ needed to titrate the sample

1.4007-milliequivalent weight of nitrogen $* 100$

W- Weight of the sample in grams.

Calculation of protein was done using this formula;

$$
\frac{P=(B-S) * N * 1.4007 * F}{W}
$$

Where;
$\mathrm{P}=$ Percentage of crude protein

$\mathrm{F}=$ Protein factor $(6.25)$

$\mathrm{B}=\mathrm{ml} \mathrm{NaOH}$ back titration of blank

$\mathrm{S}=\mathrm{NaOH}$ back titration of sample

$\mathrm{N}=$ Normality of $\mathrm{HCl}, 0.02$

$\mathrm{W}=$ Weight of samples in grams

\section{Determination of carbohydrates}

Carbohydrates content was calculated by difference (Moisture content + crude ash + crude fibre + crude fat + crude protein $)=x$.

$$
\text { Carbohydrates }=100-\mathrm{x} \text {. }
$$

\section{Determination of Beta - Carotene Content (Vitamin A)}

Standard solutions of beta carotene were prepared, that is, 1 ppm, 2 ppm, 4 ppm, 8 ppm and 10 ppm and their absorbance on SPD Shimadzu ultra violet - visible spectrometer used in calibration. A $20 \mathrm{~g}$ sample of ground spider plant morphotype was placed in $100 \mathrm{ml}$ flask, heated with acetic acid and acidified sand for extraction. The extract was concentrated with the rotary evaporator and re-extracted with $10 \mathrm{ml}$ petroleum ether. The ethereal extract was measuredby ultraviolet - visible spectrometer at $440 \mathrm{~nm}$ to obtain absorbance values. The procedure was repeated for all the samples and replicates.

A calibration curve was obtained as a linear equation from which the beta-carotene values in the samples were obtained.

\section{Determination of Ascorbic acid/ Vitamin C}

Standardization of the indophenol solution was done and the ascorbic acid equivalent calculated. A $20 \mathrm{~g}$ sample of ground spider plant morphotype was placed in a flask and acidified with trichloroacetic acid (TCA) solution. Then, filtration was done and $10 \mathrm{ml}$ of each extracted sample titrated with indophenol solution. The amount of the filtrate used for the colour of the indicator to turn pink was taken and used to obtain the concentration of the ascorbic acid in the samples. The titration was repeated twice and the results agreed within $0.1 \mathrm{ml}$. The procedure was repeated for all the samples and replicates and concentration of ascorbic acid determined.

\section{Biochemical Analysis}

Terpenoids

A $20 \mathrm{~g}$ sample of the powdered foliage material was extracted with $10 \mathrm{ml}$ of methanol in water bath at $80^{\circ} \mathrm{C}$ for 10 minutes. The concentration of constituent terpenes in the extract was determined by high performance thin layer chromatography (HPTLC) following the procedure of Sanjay, R. et al., 2013. The terpenes were separated using chloroform, glacial acetic acid, methanol and water (64:34:12:8) solvent mixture. After $24 \mathrm{~h}$, the extract was removed with a Pasteur pipette and filtered through glass wool. The sample was washed in $400 \mu \mathrm{l}$ hexane to remove any remaining terpenes [30].

The wash solvent was removed with a Pasteur pipette and 
filtered through glass wool. The volume of extract was brought to $2 \mathrm{ml}$ by addition of hexane. Twenty micro-litres of $10 \%$ paracymene were added to each extract as an internal standard. The colour and refractive factor values of TLC spots were recorded under visible light after spraying the plates with anisaldehyde-sulphuric acid reagent and heating at $60^{\circ} \mathrm{C}$ in an oven for the first $10 \mathrm{~min}$ and increased to $160^{\circ} \mathrm{C}$ for $10 \mathrm{~min}$. The concentration of terpenes was determined by integrating spotson a densitometer. [35] (William and Kinghorn 2005)

\section{Glucosinolates}

Total glucosinolates were determined by the sulfate method of [8]. A $20 \mathrm{~g}$ of the powdered foliage material was extracted with $70 \%$ ethanol on a rotary shaker at $180 \mathrm{rpm}$ for $10 \mathrm{hrs} .70 \%$ lead acetate was added to the filtrate and centrifuged after adding $6.3 \%$ sodium carbonate at 100 r.p.m for 10 minutes [28]. The pellet was dried, redisolved in chloroform and used for chromatography. The glucosinolates were separated using ethyl acetate-methanol-water (80: 10:10) solvent mixture. The colour and refractive values of the spots were recorded by observing under ultra-violet light at $254 \mathrm{~nm}$ from a densitometer, to obtain the spot intensity [24].

\section{Data analysis}

The number of feeding holes observed were transformed to $\log 10(\mathrm{n}+1)$ before analysis to standardize the variance, where $\mathrm{n}$ represented the average number of holes observed per morphotype. The transformed data were then subjected to ANOVA and Pearson's correlation coefficient (r) used to measure the strength of the association between the damage inflicted by the flea beetles and the plant metabolites. The means were separated using the protected Fischer's LSD test. Analysis was done using the statistical package Genstat 7.22, 2005[34].

\section{Results}

\section{Flea beetle damage}

The foliage damage by Flea beetles ( $P$. mashonana) was different among the three spider plant morphotypes. The flea beetles fed on the leaves resulting in characteristic shot-holes (Figure1).

The level of damage on the purple stemmed morphotype was significantly high. The green stemmed morphotype had the least damage. While the purple-green stemmed morphotype depicted a moderate damage level. The damage inflicted on the purple stemmed morphotype was three times severe than in the green stemmed morphotype $(\mathrm{F}=26.76, \mathrm{P} \leq$ 0.05) (Figure2).
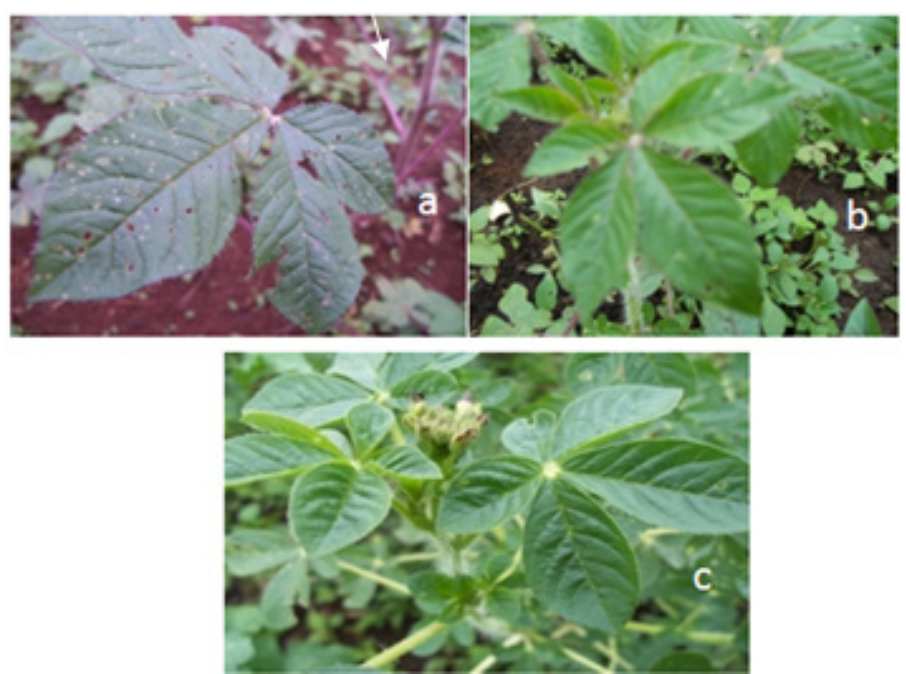

(Source, Gatahi, 2014)

Figure 1. Flea beetle shot-hole damage on leaves of different spider plant morphotypes (a) purple stemmed, (b) purple-green stemmed and (c) green stemmed.

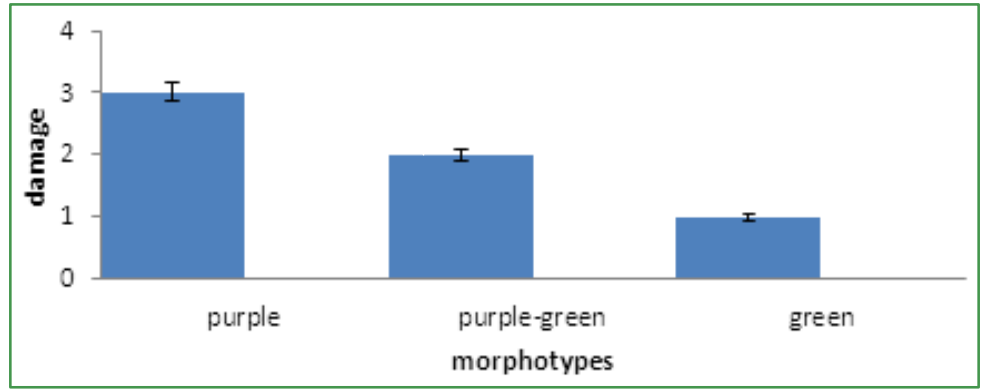

Figure 2. Mean plant damage score by the flea beetles on the three spider plant morphotypes. 
The damages were significant different among the morphotypes at $p \leq 0.05$ level. The damage recorded on the $14^{\text {th }}$ day was more than tenfold the one observed two days after infestation of the flea beetles on the purple stemmed morphotype. However, the rate of damage decreased significantly after the $10^{\text {th }}$ day with the recorded damage being insignificant as the flea beetles had reached their optimum feeding and feeding rate had reached the plateau (Table 1).

\section{Primary metabolites}

It was observed that the purple stemmed morphotype had the highest concentration of carbohydrates $(\mathrm{F}=21.18$, $\mathrm{P} \leq 0.05)$, proteins $(\mathrm{F}=10.55, \mathrm{P} \leq 0.05)$ and vitamins $\mathrm{A}$ and $\mathrm{C}$ (18.87 and 45.68, $\mathrm{P} \leq 0.05$ ) respectively. The purple-green stemmed morphotype had moderate concentration of the primary metabolites. Lastly, the green stemmed morphotype had the least primary metabolites. The protein levels did not vary between the purple-green and green stemmed morphotypes but the carbohydrates levels showed the highest increase from the green to the purple stemmed morphotypes (Table 2).

\section{Secondary metabolites}

The purple stemmed morphotype had the highest concentration of glucosinolates $(43 \%)$. The purple-green stemmed morphotype had moderate glucosinolates quantity $(37 \%)$ while the green stemmed morphotype had the least glucosinolates $(19 \%)(\mathrm{F}=49.42, \mathrm{P} \leq 0.05)$. Conversely, the green stemmed morphotype had the highest terpenoids quantities $(45 \%)$ followed by the purple-green stemmed (35\%). The purple stemmed morphotype had the least terpenoids quantities $(15 \%) \quad(\mathrm{F}=47.78, \quad \mathrm{P} \leq 0.05)$. The variation of terpenoids in the morphotypes was higher than that of glucosinolates(Table 3).

\section{Correlation of the flea beetle damage and the metabolites}

A positive correlation was found between carbohydrates, fats, vitamins, proteins, glucosinolates and the inflicted damage $\left(\mathrm{r}=0.659^{*}\right.$ to $\left.1.000^{*}\right)$. In contrast, terpenoids quantities correlated negatively with the inflicted damage by the flea beetles and the other metabolites. There was a strong correlation between the metabolites and the damage inflicted by the flea beetle; this depicted the fact that, the damage inflicted on the spider plant morphotypes was more or less stimulated by the metabolites (Table 4).

Table 1. Mean number of damage holes on spider plant morphotypes for 14 days.

\begin{tabular}{|c|c|c|c|c|c|c|c|}
\hline \multirow{2}{*}{ Treatment/Morphotype } & \multicolumn{7}{|c|}{ Time (days) } \\
\hline & & 4 & 6 & 8 & 10 & 12 & 14 \\
\hline Green stemmed & $0.0 \mathrm{a}$ & $0.7 \mathrm{a}$ & $0.7 \mathrm{a}$ & $1.1 \mathrm{a}$ & $2.4 \mathrm{a}$ & $2.7 \mathrm{~b}$ & $2.7 \mathrm{~b}$ \\
\hline Purple-green & $0.0 \mathrm{a}$ & $0.9 \mathrm{a}$ & $2.5 \mathrm{~b}$ & $4.4 \mathrm{~b}$ & $5.5 \mathrm{bc}$ & $7.2 \mathrm{c}$ & $7.6 \mathrm{c}$ \\
\hline Purple stemmed & $0.5 \mathrm{a}$ & $1.6 \mathrm{ab}$ & $4.4 \mathrm{~b}$ & $6.5 \mathrm{c}$ & $8.5 \mathrm{c}$ & $8.6 \mathrm{c}$ & $8.6 \mathrm{c}$ \\
\hline
\end{tabular}

Means linked with similar letters in a column are not significantly different $(\mathrm{p} \leq 0.05)$.

Table 2. Concentration (\%) of primary nutrients in the spider plant morphotypes leaves.

\begin{tabular}{|c|ccccc|}
\hline Morphotype & Carbohydrates & Proteins & Fats & VitaminA & VitaminC \\
\hline Green stemmed-1 & $1.7 \mathrm{a}$ & $2.6 \mathrm{a}$ & $1.4 \mathrm{a}$ & $0.2 \mathrm{a}$ & $14.3 \mathrm{a}$ \\
Purple-green -2 & $1.9 \mathrm{a}$ & $2.8 \mathrm{~b}$ & $1.6 \mathrm{~b}$ & $0.29 \mathrm{~b}$ & $15.7 \mathrm{~b}$ \\
Purple stemmed-3 & $2.5 \mathrm{~b}$ & $2.8 \mathrm{~b}$ & $1.7 \mathrm{c}$ & $0.5 \mathrm{c}$ & $16.5 \mathrm{c}$ \\
\hline
\end{tabular}

Means linked with different letters in a column are statistically different $(\mathrm{p} \leq 0.05)$.

Table 3. Concentration (\%) of secondary metabolites in the spider plant morphotypes foliage

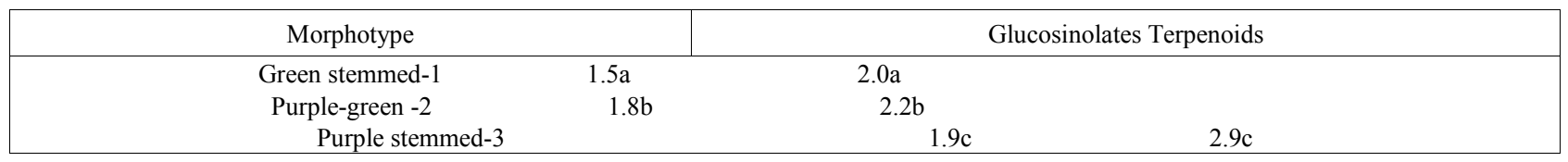

Means linked with different letters along a column are statistically different $(\mathrm{P} \leq 0.05)$.

Table4. Pearson's correlation coefficients of the relationship between spider plant morphotypes damage by the flea beetle and the metabolites.

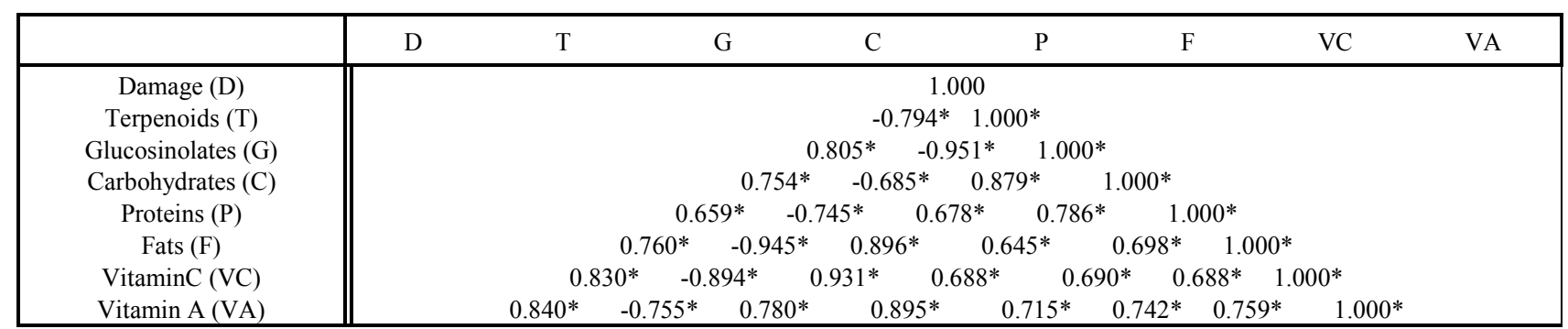

All the r-values are significant $(*)(\mathrm{p} \leq 0.05)$

(-) Negative correlation 


\section{Discussion}

\section{Flea beetle damage in spider plant morphotypes}

There was significant difference in the level of flea beetle damage among the three morphotypes. The damage ranged from severe in the purple stemmed to minimal in the green stemmed, the purple-green exhibited a moderate damage level. This study therefore, validates the Western Kenya and Rift Valley provinces communities' unreported observation that the flea beetle damage on the spider plant morphotypes is variable. The variation of the damage in spider plant morphotypes is attributed to the differences in primary and secondary metabolites as found out extensively in this study.

\section{Primary metabolites as phagostimulants}

Carbohydrates, proteins and vitamins act as major insect phagostimulants. This is informed by the fact that an insect will ingest a given amount of nutrients for optimum metabolism, the occurrence of these nutrients in high proportions in a particular plant species will result in a given insect pest preferring to feed on the plant to exploit the nutrient-ratio benefit [5] [6]. This preferential feeding in turn results in damage, thus a plant containing high quantities of these nutrients will experience a high level of damage by the insect herbivores. The variation in primary metabolites (Carbohydrates, proteins and vitamins) can explain why the purple stemmed morphotype with the highest concentration of the primary metabolites was damaged most by the flea beetle.

The variation in damage can be attributed to the neurosensory ability of flea beetles to sense nutrients concentration in a host in order to derive maximum benefits from the high primary nutrients quantities. [9] and [12]. The nutritional sensory cues than any other sensory attribute (visual or touch) have been identified for host finding and acceptance [27].

Conversely, the low primary nutrient levels in the green stemmed morphotypes discouraged feeding as the flea beetles could not derive the same nutrient benefits as in the purple stemmed morphotype. This can be referred to as negative chemotaxis where a low concentration gradient exists between the morphotypes thereby repelling flea beetles from feeding on the morphotype thus least damage inflicted. The nutrient-benefit derived from the purple-green stemmed morphotype was moderate so was the feeding, attractiveness and damage on the morphotype by the flea beetles.

Another important attractant of flea beetles to the spider plant morphotypes, is the carbohydrate-protein ratio. The nutritional analysis of spider plant depicted that the purple stemmed morphotype had the highest carbohydrates-proteins ratio of 1.22:1.00. This attracted the flea beetles resulting in the highest damage level among the 3 spider plant morphotypes. The higher the ratio the more likely a given plant species will be preferred by the insect herbivores as found out by [6]. The purple-green stemmed morphotype had a carbohydrate-protein ratio of 1.20:1.00 which was a moderate ratio while the green stemmed morphotype had the least carbohydrate-protein ratio of 1.15:1.00 and was therefore the least damaged. This nutrient-benefit feeding on spider plant morphotypes can be attributed to the fact that carbohydrates being the biggest source of energy for most organisms, an insect herbivore in this case the flea beetle will prefer to feed on the spider plant morphotype with the highest quantities of these nutrients. Similarly, proteins play a significant role in building the body of organisms, thus the spider plant morphotype with higher protein content will attract the flea beetles feeding in an attempt to gain most from ingestion of the morphotype.

Vitamins also increase the immunity and suitability of an organism to the environment. In this regard, flea beetles will therefore aim at exploiting the host with the highest quantities of the vitamins in order to enhance their suitability to the environment. Thus, the primary metabolites offer an insect direct means of assessing the nutrient quality of a potential food which allows an insect using chemotaxis to feed more on the plant species considered more "nutritious" causing more damage [20].

Supporting the above observation, [15], [5], and [19]found out that primary metabolites play a significant role in phago-stimulation, where insect herbivores will be attracted and feed more on the nutritious varieties than less nutritious ones. These nutrients therefore affect the insect herbivore gustatory responses thereby increasing the level of damage on the host plant. This therefore confirms the findings that there is a strong positive correlation between flea beetle damage and primary metabolites in spider plant morphotypes. High nutrients in the purple stemmed morphotype acted as a stimulant to the flea beetle feeding resulting in the highest damage on the foliage. The same primary metabolites significant reduction in the green stemmed morphotype can be construed to have rendered the plant less desirable to the flea beetles thus the least foliage damage.

\section{Effect of glucosinolates in spider plant morphotypes on the flea beetle damage}

Glucosinolates are water soluble group of secondary metabolites derived from glucose and amino acids and they contain sulphur and nitrogen in their structure [32]. These glucosinolates play an important role in host-pest interaction a condition that resulted after a long evolutionary process making glucosinolates a host specific attractant. Glucosinolates only affect specific insect herbivores either as attractants or repellents. Flea beetles feed only on plant containing glucosinolates a compound ubiquitous in the Brassiceae and the related families [13].

This is because glucosinolates are considered host-specific stimulants derived from the dietary experience of the foraging pests [29]. Glucosinolates play an identification role of the host to the flea beetles as they possess the necessary characteristic to trigger the physiological changes involved in development of dependence a phenomenon considered as a type of an "addiction" which is an adaptation of the flea beetles as they 
possess a nitrile-specifier protein (NSP) which attracts flea beetles to such plants. There is evidence that there exists a positive correlation between high quantities of glucosinolates and the resultant foraging of the plants by the flea beetles. [36].

Glucosinolates not only initiated but prolonged the feeding of the flea beetles which is attributed to the carbohydrate-protein rich background of glucose and amino acids which are readily absorbed forming an instant source of "succour" to the insect herbivore upon ingestion (Hobacket al. 2009). High quantities of glucosinolates in a given plant species will have a positive effect on the flea beetles infestation and damage [18] and [3]. This explains why high quantities of these glucosinolates in the purple stemmed spider plant morphotype resulted in high feeding by the flea beetles inflicting higher damage than in the green stemmed morphotype which has low quantities of glucosinolates. The low glucosinolates in the green stemmed morphotype can therefore, be construed to have made the plant less desirable for feeding by the flea beetles thus the least damage inflicted on the leaves. Whereas, the purple-green stemmed morphotype was moderately damaged as the glucosinolates quantities were also found to be moderate.

A positive correlation was found between glucosinolates quantities and the damage inflicted by the flea beetles on the spider plant morphotypes. This confirms an earlier observation by [36] that high glucosinolates quantities results in an increased foraging by the flea beetles. This can be attributed to the fact that, glucosinolates play a major role in the desirability of the spider plant as host to the flea beetles in that, the flea beetle is host specific and the higher the quantities of these glucosinolates makes the host more suitable[33]. This qualifies glucosinolates as strong phagostimulants. The correlation of glucosinolates and the flea beetle damage was very strong in this study (0.8) indicating that higher quantities of glucosinolates resulted in much feeding reflected as damage on the leaves.

However, experiments in controlled laboratory chambers found out that a 5000 fold increase in glucosinolates concentration could only lead to a 7 fold increase in feeding by the flea beetles [25]. This may be misleading as the experiment was done in a controlled environment, as the field conditions demonstrated that, provided there exists a significant difference in the concentration of glucosinolates in a particular host, then the flea beetle damage will be significantly different.

This damage may not be solely attributed to the glucosinolates, as most plants contain other phago-stimulants which play a synergistic role in host plant selection in that, host plant desirability is a function of many factors. According to[18], flavonoids are readily ingested by herbivores and humans. These flavonoids are expressed as yellow pigments and plants with high contents of these flavonoids are preferred by many pests. Other phago-stimulants include the carotenoids and anthocyanins [37].

\section{Role of terpenoids in spider plant morphotypes on flea beetle damage}

Terpenoids are aromatic secondary metabolites derived from 5-carbon isoprene units. These compounds are known for their insecticidal, antifungal, antibacterial and molluscicidal properties [24]. Terpenoids form part of the volatile cues known as olfaction repellents of insect herbivores. Unlike the other metabolites, that is, primary metabolites and glucosinolates where taste allows evaluation of the nutritional potential prior to ingestion, terpenoids have a repulsive aroma to the flea beetles and when the flea beetles are attracted by other attractants, these terpenoids have a toxic effect on the flea beetles whereby upon ingestion, the compound inhibits Adenosine Tri-phosphate (ATP) formation, results in the alkylation of the nucleophiles, disruption of hormonal activity, complexation with the protein binding with free sterols, inhibition of respiration and/or increasing the relative electron partitioning to the alternative oxidizing pathway. When the terpenoids are ingested in large quantities, the above reactions may result in death of the insect herbivore [16].

The characteristic of high terpenoids quantities makes the green stemmed morphotype the least attractive to the flea beetles which was reflected in form of the least damage inflicted on the leaves. This was in addition to the morphotype's less nutrient-benefit which made the flea beetles refrain from the morphotype as the "potential harm may not be worth the gain after consuming the host".

The repulsion of the flea beetles to the green stemmed morphotype was also informed by the well-developed olfactory lobes at the antennae of the flea beetles which can sense high terpenoids levels in the morphotypes and "keep-off". The minimum damage inflicted on the green stemmed morphotype, can be attributed to the fact that, in the event of availability of a host plant albeit with toxic chemicals, some flea beetles may have developed resistance and may have a mechanism to sequester the toxic compounds and prolong living by ingesting the food, thereby justifying the observation that all the morphotypes had some feeding damage]26].

The purple stemmed morphotype was the most suitable for the flea beetle feeding, owing to its low terpenoids quantities and high nutrients thus attracted flea beetles to feed on the foliage resulting in the highest damage inflicted. A negative correlation was observed between the terpenoids, the flea beetle damage and the other metabolites. This can be explained by the fact that, when a host is said to be desirable, most of the innate factors favour the pest. However, when a potential host is undesirable, most innate factors also deter the pests. In this study therefore, the green stemmed had the least desirable nutrients for attraction of flea beetles while at the same time had the highest feeding deterrents in the form of terpenoids which resulted in the least damage inflicted on the morphotype.

According to[14], pest repellence in plants is also attributed to cyanogenic compounds like the cyanide which exists as an unstable compound and easily disintegrates 
releasing the highly toxic and volatile cyanide. This gas easily binds the nervous system of insect herbivores and other animals killing them instantly when the cyanide is in high concentration. As a result of this, many pests tend to avoid such plants unless endowed with a natural ability for countering the toxic cyanogenic compounds. Other invertebrate anti-feedant secondary metabolites include; atropines, phytic acid and gossypol all which have a negative effect on foraging pests.

Flemming[14], attributed host plant desirability to the foliage colour, in that; insects have inherent colour preferences, mostly those colours which resemble the foliage, flower or even hosts. Different insects are attracted by different host colours with most Lepidopterous preferring yellow colours of $50-560 \mathrm{~nm}$. Hymenoptera have colour receptor in blue and ultra-violet with some species also being able to perceive red [23].

The Coleoptera insects have a high recognition for pink, purple, ultra-violet and black colours [4]. Members of the same family may prefer more than one colour like in the case of Curculionidae. In addition, colour preference may also differ at species and metamorphic level with some instars preferring different colours at different stages [31]; [10. The fact that flea beetle is a member of Coleoptera family may explain why the purple stemmed morphotype attracted the flea beetles to feed on its foliage resulting in higher damage than the green stemmed morphotype which was least attractive therefore had the least damage inflicted on the foliage. However, foliage colour cannot be the only host selection basis as insect herbivore damage is dependent on plant nutrient-benefit and chemotaxis.

\section{Conclusions}

The concentration of primary and secondary metabolites varied amongst the spider plant morphotypes. Consequently, the level of Flea beetle damage in the spider plant increased with the increasing concentration of primary metabolites and glucosinolates while it decreased with increasing terpenoid levels.

\section{Acknowledgements}

The authors thank the Department of Food Science and Technology, Jomo Kenyatta University of Agriculture and Technology for the provision of laboratory space and equipment for the determination of the metabolites.

\section{REFERENCES}

[1] Abukutsa-Onyango M.O. (2001) Market survey on African indigenous vegetable in Western Kenya. In: Proceedings of the 2nd Horticulture Seminar on Sustainable 3 Horticultural Production in the Tropics, JKUAT, Kenya, p 81-91. 1b. Abukutsa-Onyango M.O. (2004) The Diversity of Cultivated African Leafy Vegetables in Three Communities in Western Kenya. Maseno Journal of Education, Arts and Science 7 (3): 229-231.

1c. Abukutsa-Onyango M.O. (2009) Solving Kenya's Food Crisis, One Indigenous Crop at a Time. African Journal of Food Agriculture, Nutrition and Development 7: 78-99.

[2] Adango E., Onzo A., Hanna R., Atachi P., James B. (2005) Pests of Major Importance on Indigenous Leafy Vegetables. The Search for Appropriate Control Strategies. International Conference on Indigenous Vegetables and Legumes. Horticulture 752: 311-328.

[3] Agerbirk N., Orgaard M., NielsenJ. (2003) Glucosinolates, Flea Beetle Resistance, and Leaf Pubescence as Taxonomic Characters in Genus Barbarea (Brassicaceae) Phytochemistry63: 69-80.

3b. Agerbirk N. (2011) Responses of The Flea Beetles Phyllotreta nemorum and P.cruciferae to metabolically engineered Arabidopsis thaliana with an altered glucosinolate profile. Chemoecology11: 75-83.

[4] Anderbrant O., Lolquist J., Jonssen J., Marling E. (2009). Effects of the Pheromone Trap Type, Position and Colour on the Catch of the Pine Sawfly. Journal of Applied Entomology 107: 1-5.

[5] Arnod R.(1996) Feeding and Oviposition Preferences of White Pine Weevil (Coleopteracur culionidae) on Resistant and Susceptible Sitka Spruce Clones in Laboratory Bioassays. Environmental Entomology 25: 1012-1019.

[6] Bartlet E.(1996) Chemical Cues to Host-plant Selection by Insects of Oil Seed Rape. Agricultural Zoology Reviews 7: 89-96.

[7] Bailey L. (1996) Effects of Simulated and Flea Beetle Injury to Cotyledons on Growth of Drought-stressed Oils Seed Rape (Brassica napus L.) Canadian Journal of Plant Sciences 77: 475-481.

[8] Bennett R., Mellon F., Foidl N., Pratt J., Dupont M., Perkins L., Kroon P.A. (2003)Profiling glucosinolates and phenolics in vegetative and reproductive tissues of the multi-purpose trees Moringa oleifera L. (horseradish tree) and Moringa stenopetala L.J Agric Food Chem51(12):3546-53.

[9] Chapman R., Bernays E.(1995) Insect Behavior at the Leaf Surface and Learning as Aspect of Host Selection. Journal of Experimental Biology 45: 215-222.

[10] Chen Z., Kolb T., ClancyK. (2002) The role of Monoterpenes in The Resistance of Douglas fir to Western Spruce Budworm Defoliation. Journal of Chemical Ecology 28(5): 897-920.

[11] Chweya J. (1999) Genetic enhancement of indigenous vegetables in Kenya. Paper presented at workshop "Genetic Resources of Traditional Vegetables in Africa: Options for Conservation and Use, Nairobi, Kenya 20: 120-128.

[12] Cook A.(2008)Nutrient chemicals as phagostimulants for Locusta migratoria L. Ecological Entomology 2: 113-121.

[13] Cosse A., Bartelt R., Zilkowski B., Bean D.,AndressE. (2006) Behaviorally active green leaf volatiles for monitoring the leaf beetle Diorhabda elongata, a biocontrol agent of salt cedar. Journal of Chemical Ecology 32: 2695- 2708.

[14] Dicke M., Baldwin I. (2010) The evolutionary context for 
herbivore induced plant volatiles: beyond the "cry for help". Trends in Plant Science 15 (3): 167-175.

[15] Dixon W., Payne T. (1980) Attraction of entomophagous and associate insect of the southern pine beetle to beetle and hostthree produced. Journal of Entomological Experimentalis et Applicata15: 378-389.

[16] Gauthier C., Legault J., Girard-Lalancette K., Mshvildadze V., Pichette A. (2009) Haemolytic activity, cytotoxicity and membrane cell permeabilisation of synthetic and natural and lupine-and oleanane-type saponins. Medical Chemistry 17: 2002- 2008.

[17] Hall R.(2006). Plant metabolomics: from holistic hope,tohype,to hot topic. New Phytochemistry, 169: 453-468.

[18] Hartmann T. (2007) "From waste products to Ecochemicals: Fifty years research of plant secondary metabolism". Phytochemistry 68: 22-24.

[19] Hiiesaar K., Metspalu L.,Jogar K. (2006) Attractiveness and susceptibility of Brassicarapa B. napus and Sinapisalbato to the flea beetles (Coleoptera: Chrysomelidae). Agronomy Research4: 191-196.

[20] Kareiva P. (1983) Influence of vegetation texture on herbivore populations: resource concentration and herbivore movement. In R. Denno (ed.) Variable plants and herbivores in natural and managed systems. New York: Academic Press, p 259-289.

[21] KirkH.(2004) Comparing Metabolomes the chemical consequences of hybridization in Plants. New Phytochemistry 167: 613-622.

[22] K"Opondo F.B.O. (2009) Characterisation and seed quality aspects of selected types of Spider plant from Western Kenya. PhD Thesis, Department of Seed, Crop and Horticultural Sciences, Moi University, p 5-12.

[23] Lobdell C., Yong T-H., Hoffmann M. (2005) Host colour preferences and Short-range searching behaviour of the egg parasitoid Trichogramma ostriniae. Entomologia Experimenta et Applicata116:127-134.

[24] Mallikharjuna P., Rajanna L., Seetharam Y.,Sharanabasappa G. (2007) Phytochemical studies of Strychnos potatorum L. medicinal plant. E-Journal of Chemistry4: 510-518.

[25] Mc ghee (2003) Profiling glucosinolates and phenolics in vegetative and reproductive tissues of multi-purpose trees. Journal of Agriculture and food chemistry 12: 3546-3553.

[26] Michael S., Boyko E. (2006) The molecular bases of plant resistance and defense responses to aphid feeding: current status Department of Entomology, Kansas State University, Manhattan, KS 66506-4004.

[27] Moran N., Hamilton W. (1990) Low nutritive quality as defense against herbivores. Journal of Theoretical Biology 80: 247-254.

[28] Raffa K. (1999) In vitro analysis of MT-based vesicle transport by centrifugal reflection microscopy. Journal of Phytochemistry 96: 52-83.

[29] Renwick J., Lopez K. (2005). Experience based food consumption by larvae of Pierisrapae: Addiction to glucosinolates. Entomologia experimentalis et Applicata 91: 359-68.

[30] Sanjay R., Biradar B., Racheric D. (2013) Extraction of secondary metabolites and thin layer chromatography from different parts of Centellaasitica L. American Journal of Life Sciences 1 (6):243-247.

[31] Simpson S., Raubenheimer R. (1995) Feeding behavior, sensory physiology and nutrient feedback. Experimental Biology 13: 55-60.

[32] Van Dam N., Hans E., Van Dam K., Gert C., Van H., Gerrit J., Raaijmakers R., Natasja

[33] C., Postma E., Groeneweg B., Jongen W. (1998). "The glucosinolates are important determinants for taste preference and bitterness of Brussels sprouts". Journal of the Science of Food and Agriculture 78: 30.

[34] Verzani J. (2005) Using R for introductory statistics, 3rd edition. Chapman and Hall/CRC Press p 3455-3478.

[35] Wety K. (2007) Influence of plant allelochemicals on the diamond back moth in Brassicas. Ecology61: 1478-1500.

[36] WilliamP.,KinghornA. (2005) Extraction of secondary metabolites. Biotechnology20: 323-351

[37] Wittstock U., Agerbirk N., Stauber E.J., Olsen C.E., Hippler M (2004) Successful herbivore attack due to metabolic diversion of a plant chemical defense. Proceedings of Natural Academic Sciences, USA. 101: 4859-64. 